\title{
Radiofrequency Ablation versus Resection for Colorectal Cancer Liver Metastases: A Meta-Analysis
}

\author{
Mingzhe Weng', Yong Zhang', Di Zhou, Yong Yang, Zhaohui Tang, Mingning Zhao, Zhiwei Quan*, \\ Wei Gong*
}

Department of General Surgery, Xinhua Hospital, School of Medicine, Shanghai Jiaotong University, Shanghai, China

\begin{abstract}
Background: No randomized controlled trial (RCT) has yet been performed to provide the evidence to clarify the therapeutic debate on liver resection (LR) and radiofrequency ablation (RFA) in treating colorectal liver metastases (CLM). The meta-analysis was performed to summarize the evidence mostly from retrospective clinical trials and to investigate the effect of LR and RFA.

Methodology/Principal Findings: Systematic literature search of clinical studies was carried out to compare RFA and LR for CLM in Pubmed, Embase and the Cochrane Library Central databases. The meta-analysis was performed using risk ratio (RR) and random effect model, in which $95 \%$ confidence intervals $(95 \% \mathrm{Cl})$ for RR were calculated. Primary outcomes were the overall survival (OS) and disease-free survival (DFS) at 3 and 5 years plus mortality and morbidity. 1 prospective study and 12 retrospective studies were finally eligible for meta-analysis. LR was significantly superior to RFA in 3 -year OS (RR 1.377, 95\% Cl: 1.246-1.522); 5-year OS (RR: 1.474, 95\%Cl: 1.284-1.692); 3-year DFS (RR 1.735, 95\% Cl: 1.483-2.029) and 5-year DFS (RR $2.227,95 \%$ Cl: $1.823-2.720$ ). The postoperative morbidity was higher in LR (RR: $2.495,95 \%$ Cl: $1.881-3.308$ ), but no significant difference was found in mortality between LR and RFA. The data from the 3 subgroups (tumor $<3 \mathrm{~cm}$; solitary tumor; open surgery or laparoscopic approach) showed significantly better OS and DFS in patients who received surgical resection.

Conclusions/Significances: Although multiple confounders exist in the clinical trials especially the bias in patient selection, LR was significantly superior to RFA in the treatment of CLM, even when conditions limited to tumor $<3 \mathrm{~cm}$, solitary tumor and open surgery or laparoscopic (lap) approach. Therefore, caution should be taken when treating CLM with RFA before more supportive evidences for RFA from RCTs are obtained.
\end{abstract}

Citation: Weng M, Zhang Y, Zhou D, Yang Y, Tang Z, et al. (2012) Radiofrequency Ablation versus Resection for Colorectal Cancer Liver Metastases: A MetaAnalysis. PLoS ONE 7(9): e45493. doi:10.1371/journal.pone.0045493

Editor: Jin Q. Cheng, H. Lee Moffitt Cancer Center \& Research Institute, United States of America

Received March 5, 2012; Accepted August 20, 2012; Published September 21, 2012

Copyright: (c) 2012 Weng et al. This is an open-access article distributed under the terms of the Creative Commons Attribution License, which permits unrestricted use, distribution, and reproduction in any medium, provided the original author and source are credited.

Funding: Funding agencies: China Natural Science Project to ZWQ (30972919); Shanghai Scientific Bureau International Cooperation Project to WG (10410700100); and Shanghai Municipal Health Bureau funding to WG (2009064). The funders had no role in study design, data collection and analysis, decision to publish, or preparation of the manuscript.

Competing Interests: The authors have declared that no competing interests exist.

*E-mail: gongweius@hotmail.com (WG); zhiwquan@yahoo.com.cn (ZWQ)

9 These authors contributed equally to this work.

\section{Introduction}

Colorectal carcinoma (CRC) is the fourth most common malignancy worldwide [1], and raises serious concern in view of most cases developing metastases at presentation or during treatment. Liver as the only or initial metastatic site is found in $20 \%$ of the CRC patients [2]. Surgery is considered as the golden standard in the treatment of colorectal liver metastases (CLM), with 5-year overall survival rate ranging from $27 \%$ to $58 \%$ [3-5]. Nevertheless, only $10-25 \%$ of patients with CLM are eligible for surgical resection in terms of the extent and location of the disease and concurrent medical conditions [6]

Ablative therapeutic methods have been introduced as alternative measures to treat liver tumors such as cryoablation [7], percutaneous ethanol injection (PEI) [8], acetic acid injection [9], microwave coagulation [10], transcatheter arterialchemoembolization (TACE) [11] and radiofrequency ablation [12]. Among them, RFA is regarded as a promising and powerful technique for tumor destruction, and is recommended as the primary ablative therapy for CLM at most centers [13]. Nowadays, the RFA technology enables a single probe insertion to ablate a spherical zone exceeding $5 \mathrm{~cm}$ in diameter in vivo, which substantially expands its application in clinical practice [14].

The advantages of RFA treatment such as minimal invasiveness, better safety, equivalent local control and survival to liver resection (LR) have influenced the treatment strategy for hepatocellular carcinomas (HCG) and CLM [15-17]. Recently, two randomized clinical trials showed equivalent survival after percutaneous RFA and LR for HCC $<5 \mathrm{~cm}[18,19]$. However, for those patients with CLM eligible for surgical treatment, whether RFA or LR is the better choice remains controversial. Two recent papers proposed a randomized trial comparing resection and radiofrequency ablation for resectable CLM [20-21]. We performed a meta-analysis of all the studies directly comparing LR and RFA in the treatment of CLM, preparing for the following RCTs. 


\section{Materials and Methods}

\section{Literature Search}

QUOROM guidelines were followed for conducting metaanalysis. The study design and report were adhered to the PRISMA Statement guidelines (PRISMA S1). A systematic literature search was performed independently by two of the authors (WMZ and TZH) using Pubmed, Embase and the Cochrane Library Central at two different medical science information centers respectively affiliated to Fudan University and Shanghai Jiao Tong University. The search was limited to humans. No restriction was set for languages or date of publication. The search strategy was based on the following Medical Subject Heading terms (MeSH) and text words: "radiofrequency ablation", "radio frequency ablation", "resection", "colorectal tumor", "colorectal neoplasm", "colorectal cancer", "liver", "metastases", "metastasis". The search was broadened by extensive cross-checking of the reference lists of all retrieved articles. When further information was required, the corresponding authors of relevant papers were contacted by the reviewers.

\section{Data Extraction}

Data extraction was performed independently by the same investigators, and in the case of discrepancy, the decision was made by discussion with a third author $(\mathrm{GW})$. The main extracted data included: (1) First author, the year of publication and the study type; (2) The number and characteristics of patients, (3) The outcome of the trials including the overall survival (OS) and disease-free survival (DFS) at 3 and 5 years plus mortality and morbidity.

\section{Inclusion Criteria}

The following criteria were fulfilled for the studies included in the meta-analysis: (1) The studies comparing the original outcomes of RFA and LR in the treatment of colorectal cancer liver metastases; (2) The studies reporting at least 3- or 5-year overall survival; (3) If more than one studies were reported by the same institute or author, only the most recent or the highest level of studies were included.

\section{Exclusion Criteria}

The following studies were excluded: (1) the original studies only assessing outcome of either RFA or LR; (2) those not using OS or DFS or with a follow up of less than 2 years; (3) those recruiting CLM patients treated with a combined therapy (LR+RFA); (4) review articles, letters, comments, case reports.

\section{Subgroup analysis}

3 subgroups were evaluated: (1) the maximal tumor diameter was less than $3 \mathrm{~cm}$; (2) solitary tumor; (3) RFA was conducted under laparoscopic or open surgery condition.

\section{Statistical Analysis}

The meta-analysis was performed using Statistics/Data Analysis version 11.0 (Stata, Texas, USA). Calculation for dichotomous variables was carried out using the risk ratio (RR) and their 95\% $\mathrm{CI}$ as the summary statistic. Owing to the between-study variability of sample size and detection methods, overall estimates were calculated by using the random effect model. Quantitative assessment of heterogeneity was explored by chi-square test with significance set at $\mathrm{P}$ value 0.10 and was measured using I-squared statistic. The potential for publication bias was graphically explored through the production of funnel plots, and tested for significance with Begg's test for asymmetry [22]. All statistical data were considered significant if the probability of a chance occurrence was less than $5 \%(\mathrm{p}<0.05)$.

\section{Results}

\section{Selection of trials}

Of the 17 clinical trials initially met the inclusion criteria, 2 didn't display the specific comparison of the effects of RFA and LR [37,38], 1 did not use 3- or 5-year OS [39] and 1 with no original data [40]. Finally, 13 studies [24-36] between 2003 and 2011 matched the selection criteria and were processed with metaanalysis (Table 1). Given the shortage of prospective randomized trials, 12 were retrospective studies and 1 was prospective study. 5 studies used percutaneous RFA [23,25,26,32,33], 2 studies used RFA during open surgery [24,28], while the remaining 6 trials utilized RFA either via percutaneous or open surgery. Totally, 1886 subjects were involved in this meta-analysis, 1266 treated with LR and 620 treated with RFA. The pooled analysis of the patients' characteristics was as follows (LR vs. RFA): the mean male/female rate was 1.55 vs. 1.32 ; the mean age was 60.33 vs. 61.93; the mean tumor size and number were $3.35 \mathrm{~cm}$ vs. $2.52 \mathrm{~cm}$ and 1.28 vs. 1.38 , respectively; the mean tumor stage $\alpha / \beta-\chi$ rate and tumor node positive/negative rate were 0.21 vs. 0.31 and 1.23 vs. 1.11, respectively (Table 2, Table 3).

\section{Overall survival}

The statistic data was significantly favorable to LR group at 3year survival (11 trials reported the data, RR: $1.377,95 \%$ CI: 1.246-1.522) and 5-year survival (11 trials reported the data, RR: 1.474, 95\%CI: 1.284-1.692) (Figure 1). Moreover, stratified metaanalysis showed the LR group had better long-term survival than RFA group in all 3 subgroups (Table 4).

\section{Disease-free survival}

As Table 3 shows, the 3-year DFS (RR 1.735, 95\% CI: $1.483-$ 3.385) and 5-year DFS (RR 2.227, 95\% CI: 1.823-2.720) was significantly higher in the LR group (Figure 1). The significantly higher DFS rates in LR group were also observed in all 3 subgroups.

\section{Safety}

The postoperative morbidity was significantly higher in the LR group than in the RFA group. (9 trials reported the data, RR: 2.495, 95\% CI: 1.881-3.308). However, no difference was observed in terms of postoperative mortality (8 trials involved, RR: 1.391, 95\% CI: 0.306-6.326) (Table 5). The mean length of hospital stay was $11.02 \pm 0.11$ days for LR group and $4.05 \pm 0.10$ days for RFA (standardized mean difference: 3.284, 95\% CI: $3.052-3.516, \mathrm{P}<0.001)$.

\section{Publication Bias}

The funnel plot did not show evidence of publication bias by Begg's test in 3-year survival $(z=0.41, \operatorname{Pr}>|z|=0.732$, continuity corrected), 5-year survival $(z=-1.51, \operatorname{Pr}>|z|=0.15$, continuity corrected), 3-year DFS $(\mathrm{z}=-1.25, \operatorname{Pr}>|\mathrm{z}|=0.251$, continuity corrected $)$, and 5-year $\operatorname{DFS}(z=-0.19, \operatorname{Pr}>|z|=1.0$, continuity corrected) (Figure 2).

\section{Discussion}

Surgical resection currently is the gold standard in the treatment of resectable colorectal cancer liver metastases [41]. 5-year survival 


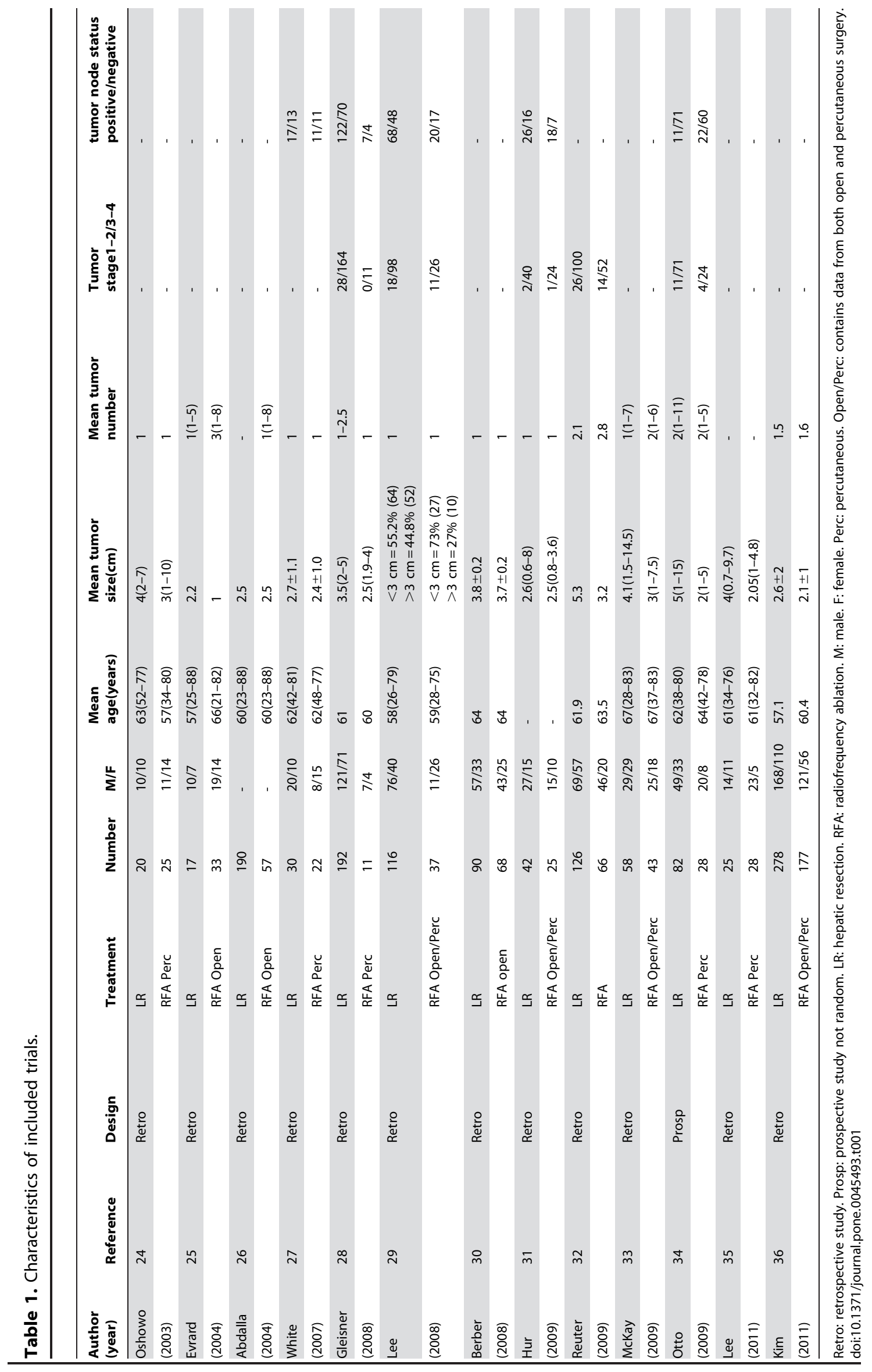


Table 2. Raw data of each included study.

\begin{tabular}{|c|c|c|c|c|c|c|c|c|c|c|c|c|}
\hline \multirow[t]{2}{*}{$\begin{array}{l}\text { Author } \\
\text { (year) }\end{array}$} & \multirow[t]{2}{*}{ Treatment } & \multirow[t]{2}{*}{$\mathbf{n}$} & \multicolumn{3}{|c|}{ Overall Survival } & \multirow[b]{2}{*}{ 3year OS } & \multirow[b]{2}{*}{ 5year OS } & \multicolumn{5}{|c|}{ Disease-free Survival } \\
\hline & & & Hazard ratio & $95 \% \mathrm{Cl}$ & P-value & & & Hazard ratio & $95 \% \mathrm{Cl}$ & P-value & 3year DFS & 5year DFS \\
\hline Oshowo & $\mathrm{LR}$ & 20 & - & - & - & $55 \%$ & $42 \%$ & - & - & - & - & - \\
\hline (2003) & RFA (Perc) & 25 & & & & $53 \%$ & $36 \%$ & & & & - & - \\
\hline Evrard & LR & 17 & - & - & - & - & - & - & - & - & - & - \\
\hline (2004) & RFA (Open) & 33 & & & & - & _- & & & & _- & _- \\
\hline Abdalla & LR & 190 & 2.79 & $1.68-4.62$ & 0.001 & $73 \%$ & $58 \%$ & 2.6 & $1.84-3.68$ & 0.001 & $40 \%$ & $31 \%$ \\
\hline (2004) & RFA Open & 57 & & & & $37 \%$ & $21 \%$ & & & & $9 \%$ & $7 \%$ \\
\hline White & $L R$ & 30 & - & _- & _- & $82 \%$ & $57 \%$ & _- & - & _- & $51 \%$ & $36 \%$ \\
\hline (2007) & RFA Perc & 22 & & & & $84 \%$ & $42 \%$ & & & & $0 \%$ & $0 \%$ \\
\hline Gleisner & LR & 192 & 1.77 & $0.75-4.21$ & 0.01 & $72.00 \%$ & $57.40 \%$ & 1.41 & $0.59-3.35$ & 0.01 & $41 \%$ & $41 \%$ \\
\hline (2008) & RFA Perc & 11 & & & & $51.20 \%$ & $28.30 \%$ & & & & $9 \%$ & $0 \%$ \\
\hline Lee & LR & 116 & - & _- & - & $51 \%$ & $66 \%$ & _- & - & _- & $88 \%$ & $85 \%$ \\
\hline (2008) & RFA Open/perc & 37 & & & & $32 \%$ & $49 \%$ & & & & $53 \%$ & $43 \%$ \\
\hline Berber & LR & 90 & 1.24 & $0.91-1.66$ & 0.16 & $70 \%$ & $40 \%$ & _- & - & _- & $45 \%$ & $38 \%$ \\
\hline (2008) & RFA open & 68 & & & & $35 \%$ & $30 \%$ & & & & $29 \%$ & $0 \%$ \\
\hline Hur & LR & 42 & 2.65 & $1.14-6.17$ & 0.024 & $70 \%$ & $50.10 \%$ & 4.61 & $1.16-18.36$ & 60.03 & $90 \%$ & $89.70 \%$ \\
\hline (2009) & RFA Open/perc & 25 & & & & $60 \%$ & $25.50 \%$ & & & & $76 \%$ & $69.70 \%$ \\
\hline Otto & LR & 82 & 1.035 & $\begin{array}{l}0.478- \\
2.239\end{array}$ & 0.93 & $60 \%$ & $51 \%$ & 0.523 & $\begin{array}{l}0.304- \\
0.901\end{array}$ & 0.017 & $40 \%$ & $30 \%$ \\
\hline (2009) & RFA Perc & 28 & & & & $67 \%$ & $48 \%$ & & & & $18 \%$ & $18 \%$ \\
\hline Reuter & LR & 126 & _- & _- & _- & $55 \%$ & $23 \%$ & _- & _- & _- & $42 \%$ & $24 \%$ \\
\hline (2009) & RFA & 66 & & & & $42 \%$ & $21 \%$ & & & & $24 \%$ & $8 \%$ \\
\hline McKay & LR & 58 & 2.78 & $1.43-5.26$ & 0.02 & $60 \%$ & $43 \%$ & - & - & - & - & - \\
\hline (2009) & RFA & 43 & & & & $39 \%$ & $23 \%$ & & & & _- & _- \\
\hline Lee & LR & 25 & 1.74 & $1.37-2.21$ & 0.001 & $68 \%$ & $44.00 \%$ & 1.4 & $1.12-1.75$ & 0.004 & $40 \%$ & $12 \%$ \\
\hline (2011) & RFA Perc & 28 & & & & $35.70 \%$ & $17.90 \%$ & & & & $10.70 \%$ & $0 \%$ \\
\hline Kim & LR & 278 & 3.613 & $\begin{array}{l}1.422- \\
9.193\end{array}$ & 0.007 & $59 \%$ & $44.60 \%$ & 3.821 & $1.518-9.62$ & 20.004 & $32 \%$ & $28 \%$ \\
\hline (2011) & RFA & 177 & & & & $49.70 \%$ & $35.60 \%$ & & & & $26 \%$ & $20.30 \%$ \\
\hline
\end{tabular}

LR: liver resection. RFA: radiofrequency ablation. Cl: confidence interval. Perc: percutaneous. Open/Perc: contains data from both open and percutaneous surgery. doi:10.1371/journal.pone.0045493.t002

in resected patients was about $25 \%$ versus $0 \%$ for the untreated in some early retrospective studies [42]. It has been reported recently that improved surgical techniques brought the 5-year survival rates up to $30-35 \%$ [41]. However, traditional hepatectomy is being

Table 3. Summary of patient's characteristics.

\begin{tabular}{|c|c|c|c|c|}
\hline Characteristics & LR & $\mathbf{N}_{\mathbf{L R}}$ & RFA & $\mathbf{N}_{\text {RFA }}$ \\
\hline$M / F$ & $1.55 \pm 0.26$ & 1076 & $1.32 \pm 0.56$ & 563 \\
\hline age & $60.33 \pm 2.54$ & 41224 & $61.93 \pm 2.55$ & 5595 \\
\hline Mean tumor size $(\mathrm{cm})$ & $3.35 \pm 0.98$ & 1150 & $2.52 \pm 0.67$ & 583 \\
\hline Mean tumor number & $1.28 \pm 0.21$ & 1051 & $1.38 \pm 0.42$ & 535 \\
\hline Tumor stage I-II/III-IV rate & $0.21 \pm 0.05$ & 558 & $0.31 \pm 0.10$ & 167 \\
\hline $\begin{array}{l}\text { tumor node status positive/ } \\
\text { negative rate }\end{array}$ & $1.23 \pm 0.68$ & 462 & $1.11 \pm 0.96$ & 123 \\
\hline
\end{tabular}

LR: liver resection. RFA: radiofrequency ablation. M: male. F: female.

doi:10.1371/journal.pone.0045493.t003 challenged by a number of ablative techniques, for instance, microwave ablation, laser ablation, cryoablation and radiofrequency ablation which allow a wide varialblity in the reported 5year survival rate (14-55\%) for the unresectalbe colorectal liver metastases [6-12].

Two recently published randomized clinical trials (RCTs) showed equivalent survival rate of percutaneous RFA to surgical resection for hepatocellular caricinomas $(\mathrm{HCG})<5 \mathrm{~cm}$. While RCTs for CLM patients are pending, there is a rising demand for comparing as much evidence as possible to clarify whether RFA or LR is better in the treatment of CLM $[18,19]$. We performed this meta-analysis which showed that in the treatment of CLM, LR was superior to RFA. LR had a significant higher survival at 3 and 5 years as well as disease-free survival at 3 and 5 years. It was reported that better prognosis was achieved after RFA when maximal size of the tumors was less than $3 \mathrm{~cm}$ as consequence of the disease free margins [43] which the authors claimed that the tumor should not exceed $3.5 \mathrm{~cm}$ in longest axis to obtain a safety margin of $1 \mathrm{~cm}$ all around the lesion [44]. However, in our 
A

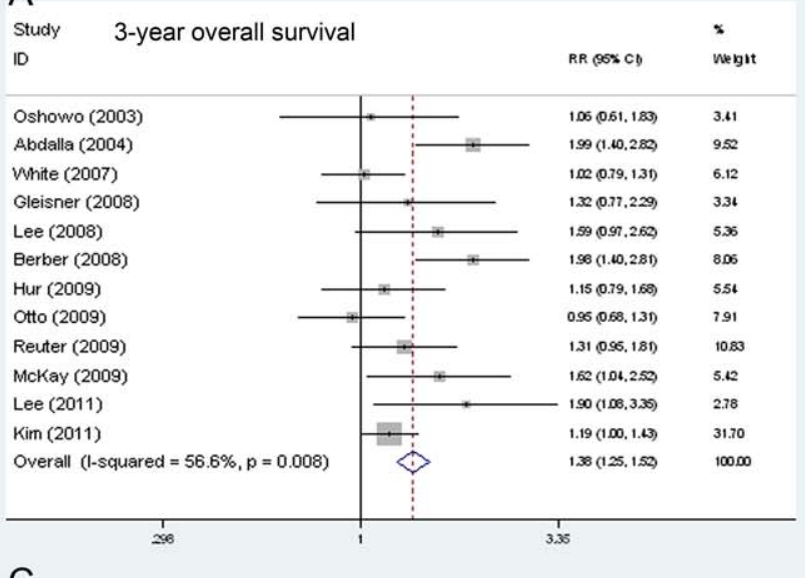

C

study 3-year disease-free survival

ID

\section{Abdalla (2004)}

White (2007)

Gleisner (2008)

Lee (2008)

Berber (2008)

Hur (2009)

Otto (2009)

Reuter (2009)

Lee (2011)

Kim (2011)

Overall (1-squared $=65.4 \%, p=0.002$ )

$\operatorname{sen} \frac{1}{2}$

E

Study Hazard ratio of overall survival

ID

\section{Abdalla (2004)}

Gleisner (2008)

Berber (2008)

Hur (2009)

Otto (2009)

McKay (2009)

Kim (2011)

Lee (2011)

Overall (l-squared $=0.0 \%, p=0.781$ )

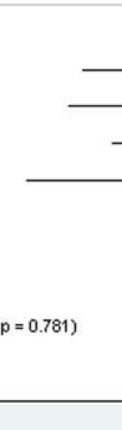

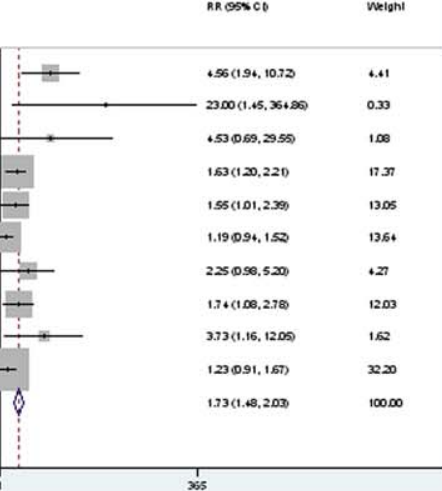

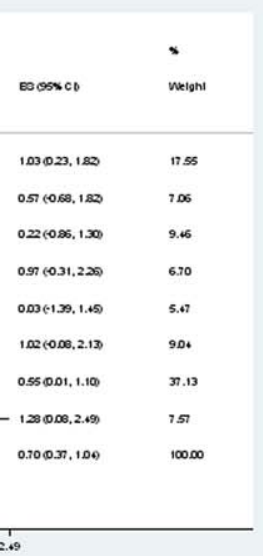

B Study 5-year overall survival ID

Oshowo (2003) A.bdalla (2004) White (2007)

Gleisner (2008)

Lee (2008)

Berber (2008)

Hur (2009)

Otto (2009)

Reuter (2009)

McKay (2009)

Lee (2011)

Kim (2011)

Overall (I-squared $=21.7 \%, p=0.230$ )

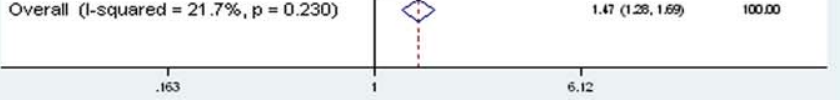

D

Study 5-year disease-free survival

ID

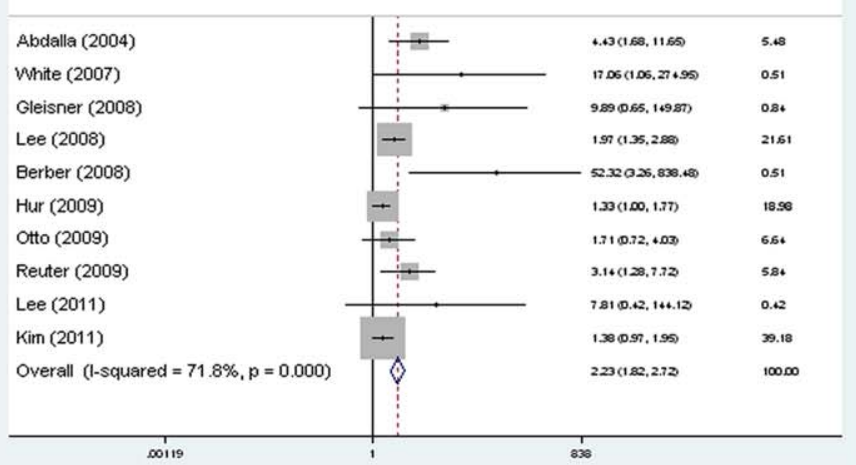

$\mathrm{F}$

Study Hazard ratio of disease-free survival

ID

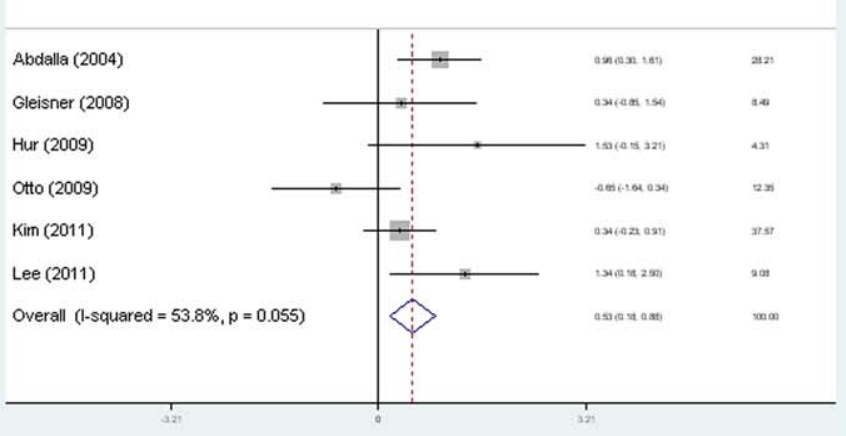

Figure 1. Results of the meta-analysis on overall survival, disease-free survival, overall survival hazard ratio and disease-free survival hazard ratio. A. Results of the meta-analysis on overall survival at 3 years. B. Results of the meta-analysis on overall survival at 5 years. $C$. Results of the meta-analysis on disease-free survival at 3 years. D. Results of the meta-analysis on disease-free survival at 5 years. E. Results of the meta-analysis on overall survival hazard ratio. F. Results of the meta-analysis on disease-free survival hazard ratio.

doi:10.1371/journal.pone.0045493.g001

subgroup of tumor size $<3 \mathrm{~cm}$, the data did not show favorable outcomes.

It was also reported that a significant difference in the number of patients with solitary tumor between the LR and RFA leaded to the prognostic inequality $[24,27,29-31,36]$. However, we found that patients with solitary tumor had higher OS and DFS after LR. Moreover, two studies showed lower local recurrence rates for open surgical approach comparing with percutaneous approach in RFA $[45,46]$, and this meta-analysis demonstrated that even the open surgical ablation group was still unable to match the survival of LR. It is suggested that although tumor $<3 \mathrm{~cm}$, solitary tumor and open surgery or laparoscopic (lap) approach are the prognostic factors favorable to RFA, performing RFA in such scenarios still cannot achieve a comparable OS and DFS to those of LR. 
Table 4. Results of the meta-analysis for LR vs RFA in treatment of CLM.

\begin{tabular}{|c|c|c|c|c|c|c|c|c|}
\hline Variables & Time interval & Subgroups & Nsuvival/N & Nsuvival/ $\mathbf{N}_{\text {RFA }}$ & $\begin{array}{l}\text { LR vs RFA } \\
\text { RR }(95 \% \mathrm{Cl})\end{array}$ & $\mathbf{p}$ & $1^{2}$ & Ref. \\
\hline \multirow[t]{10}{*}{ Overall survival } & 3 years & Total & $802 / 1249$ & $269 / 587$ & $1.377(1.246-1.522)$ & $<0.001$ & $56.6 \%$ & $26-34$ \\
\hline & & $<3 \mathrm{~cm}$ & $157 / 213$ & $33 / 72$ & $1.680(1.279-2.208)$ & $<0.001$ & $90.0 \%$ & 26,31 \\
\hline & & Solitary & $306 / 481$ & $150 / 290$ & $1.263(1.109-1.439)$ & $<0.001$ & $64.0 \%$ & $24,27,29-31,36$ \\
\hline & & Open & $139 / 280$ & $29 / 125$ & $2.549(1.801-3.609)$ & $<0.001$ & $73.4 \%$ & 26,30 \\
\hline & & Perc & 240/349 & $55 / 114$ & $1.143(0.947-1.379)$ & 0.014 & $48.8 \%$ & $24,27,28,34,35$ \\
\hline & 5 years & Total & $610 / 1249$ & $182 / 587$ & $1.474(1.284-1.692)$ & $<0.001$ & $21.7 \%$ & $26-36$ \\
\hline & & $<3 \mathrm{~cm}$ & $123 / 213$ & 20/72 & $2.168(1.442-3.260)$ & $<0.001$ & $84.4 \%$ & 26,31 \\
\hline & & Solitary & $250 / 481$ & $119 / 290$ & $1.209(1.025-1.426)$ & 0.024 & $0.0 \%$ & $24,27,29-31,36$ \\
\hline & & Open & $95 / 280$ & $24 / 125$ & $2.012(1.321-3.064)$ & 0.001 & $81.8 \%$ & 26,30 \\
\hline & & Perc & $188 / 349$ & $39 / 114$ & $1.426(1.062-1.915)$ & 0.018 & $0 \%$ & $24,27,28,34,35$ \\
\hline \multirow[t]{10}{*}{ Disease-free survival } & 3 years & Total & $539 / 1171$ & $135 / 519$ & $1.735(1.483-2.029)$ & $<0.001$ & $65.4 \%$ & $26-32,34-36$ \\
\hline & & $<3 \mathrm{~cm}$ & $98 / 213$ & $18 / 72$ & $2.238(1.480-3.385)$ & $<0.001$ & $97.7 \%$ & 26,31 \\
\hline & & Solitary & $343 / 653$ & $101 / 276$ & $1.435(1.212-1.699)$ & $<0.001$ & $61.5 \%$ & $27-31,36$ \\
\hline & & Open & $117 / 280$ & $25 / 125$ & $2.309(1.544-3.453)$ & $<0.001$ & $82.5 \%$ & 26,30 \\
\hline & & Perc & $137 / 329$ & 9/114 & $3.853(2.065-7.190)$ & $<0.001$ & $6.6 \%$ & $27,28,34,35$ \\
\hline & 5 years & Total & $456 / 1171$ & $83 / 519$ & $2.227(1.823-2.720)$ & $<0.001$ & $71.8 \%$ & $26-32,34-36$ \\
\hline & & $<3 \mathrm{~cm}$ & $81 / 213$ & $17 / 72$ & $1.104(1.039-1.173)$ & 0.001 & $97.9 \%$ & 26,31 \\
\hline & & Solitary & $324 / 653$ & $64 / 276$ & $2.014(1.624-2.499)$ & $<0.001$ & $78.8 \%$ & $27-31,36$ \\
\hline & & Open & $93 / 280$ & $4 / 125$ & $8.477(3.565-20.156$ & $<0.001$ & $70.5 \%$ & 26,30 \\
\hline & & Perc & $118 / 329$ & $5 / 114$ & $3.763(1.762-8.033)$ & 0.001 & $41.3 \%$ & $27,28,34,35$ \\
\hline
\end{tabular}

LR: liver resection. RFA: radiofrequency ablation. RR: risk ratio. $\mathrm{Cl}$ : confidence interval. $<3 \mathrm{~cm}$ refers to the maximal tumor diameter was less than $3 \mathrm{~cm}$. Open means that RFA was conducted under open surgery condition. Perc means that RFA was conducted percutaneously.

doi:10.1371/journal.pone.0045493.t004

It could be explained in several aspects. Firstly, in the retrospective studies, "unresectable" CLM as a main indication for RFA may lead to inevitable selection bias. "Unresectable" patients refer to those who would not be tolerant to surgery because of poor healthy condition, inadequate functional reserve of the remaining liver or special locations of the metastatic tumor such as bilobes of the liver or proximity to large vessels. Secondly, the resection allows better intraoperative staging and postoperative pathological evaluation, which helps make an optimized postoperative treatment strategy of chemotherapy and biotherapy. Thirdly, an estimated $0-1.4 \%$ risk of electrode track seeding was reported to occur after percutaneous RFA, leaving the possibility of distant recurrence [47].

On the other hand, we should not neglect the non-oncological advantages of RFA over hepatic resection, such as lower complication rate $(18.3 \%$ vs $3.9 \%, \mathrm{p}<0.01)$, and shorter hospital stay $(9.2 \pm 0.6$ vs $3.9 \pm 0.4, \mathrm{p}<0.01)$. Most patients undergoing percutaneous RFA only require an overnight stay, while elderly patients stay 2-3 days [48]. For laparoscopic and open RFA, the mean hospital day is 1-3 days and 4-7 days respectively [49]. RFA has a big advantage over the LR group with a mean hospital stay of 12.5 days.

Shortly after we finished our meta-analysis, a similar paper which focused on solitary CLM was recently published by Wu et al [50]. Consistent with our findings, they found that LR group had better 5 -year survival rate and comparable postoperative mortality comparing with RFA group. However, in contrast to their result that two groups had no difference in terms of postoperative morbidity, our study found that the postoperative morbidity was significantly higher in the LR group than in the RFA group. This might result from different data we adopted in our study in which we examined all the colorectal liver metastasis including multiple liver metastasis.

The only way to balance the selection bias and consequently find out whether RFA can reach equal outcome is to hold a randomized controlled trial. Mulier et al [51] proposed a randomized trial of RFA versus resection for resectable colorectal liver metastases with the following inclusion criteria: resectable CLM; no contraindication for RFA; only small tumors $(<3 \mathrm{~cm})$; RFA only by open surgical approach; only tumors away from large

Table 5. Meta-analysis of the safety of liver resection and radiofrequency ablation.

\begin{tabular}{|c|c|c|c|c|c|c|c|c|}
\hline Variables & LR & $\mathbf{N}_{\text {Morbidity }} / \mathbf{N}_{L R}$ & RFA & $\mathbf{N}_{\text {Motality }} / \mathbf{N}_{\mathrm{RFA}}$ & RR $(95 \% \mathrm{Cl})$ & $\mathbf{p}$ & $1^{2}$ & Reference \\
\hline Morbidity & $24.10 \%$ & $220 / 913$ & $9.98 \%$ & $47 / 471$ & $2.495(1.881-3.308)$ & 0.009 & $60.70 \%$ & $22,26,28-34$ \\
\hline Mortality & $0.31 \%$ & $2 / 639$ & $0.34 \%$ & $1 / 294$ & $1.391(0.306-6.326)$ & 0.407 & $0.0 \%$ & $22,26,28-32$ \\
\hline
\end{tabular}

LR: liver resection. RFA: radiofrequency ablation.

doi:10.1371/journal.pone.0045493.t005 
A

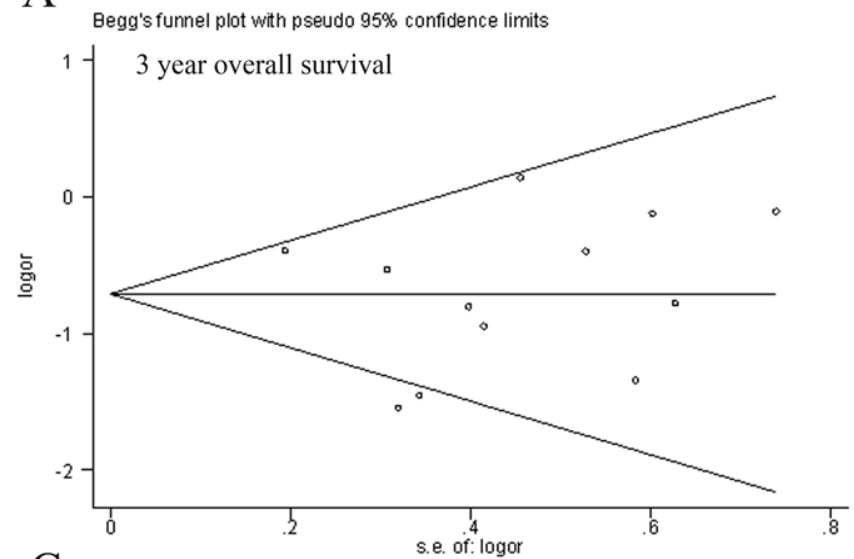

$\mathrm{C}$

Begg's funnel plot with pseudo $95 \%$ confidence limits

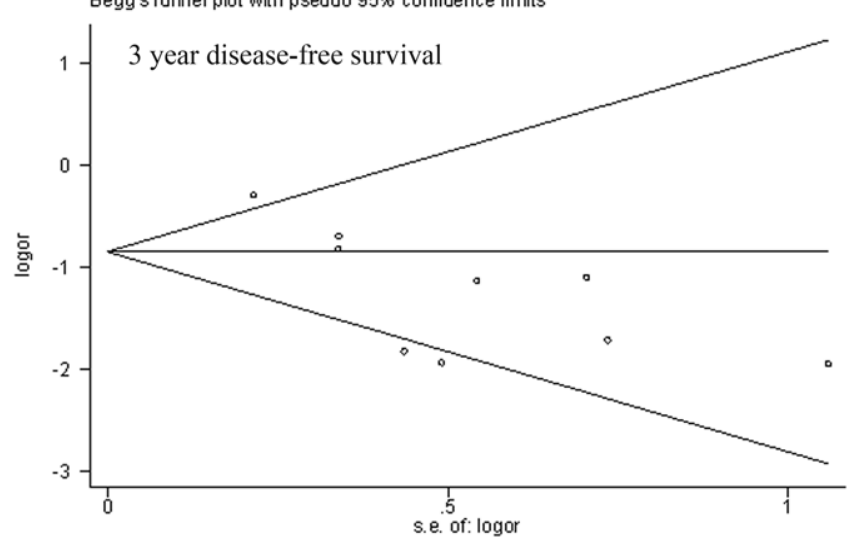

$\mathrm{B}$

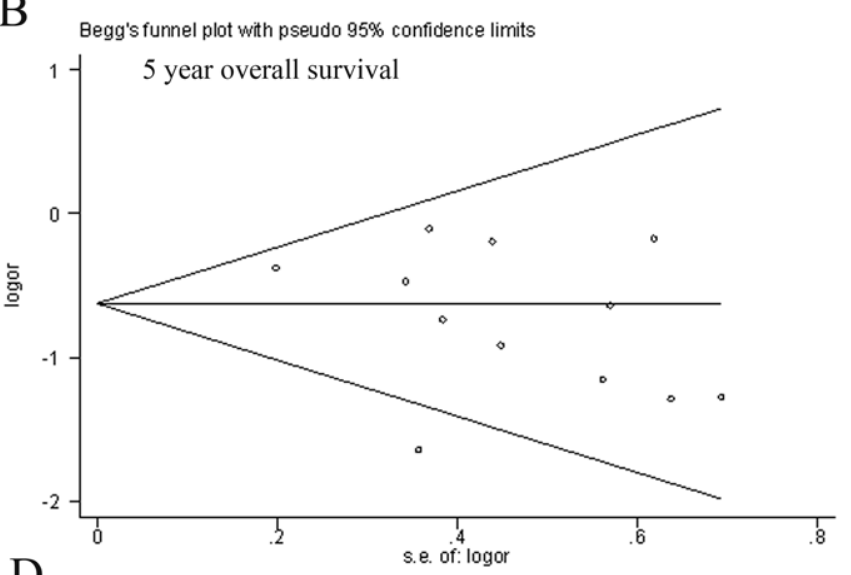

$\mathrm{D}$

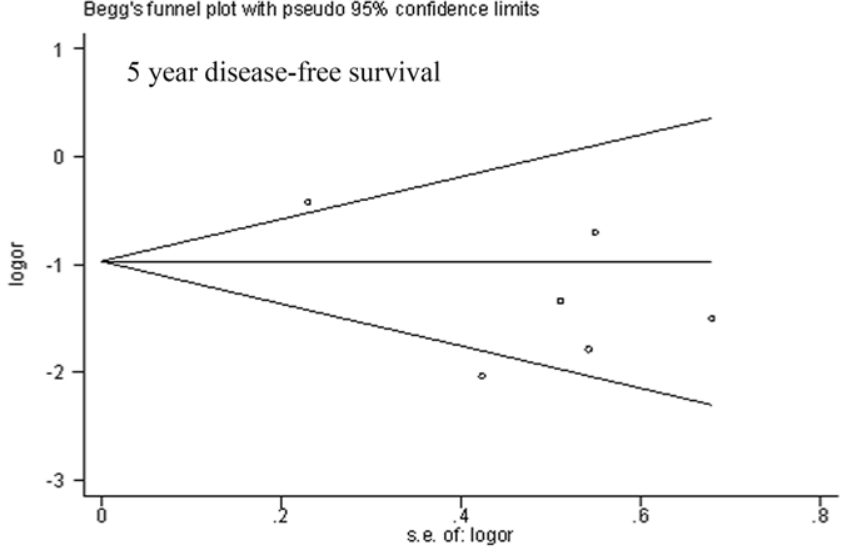

Figure 2. Funnel plot to detect publication bias. A. Begg's test result of 3-year survival. B. Begg's test result of 5-year survival. C. Begg's test result of 3-year disease-free survival. D. Begg's test result of 5-year disease-free survival.

doi:10.1371/journal.pone.0045493.g002

vessels unless a Pringle maneuver can be safely applied; RFA only by experienced physicians; intentional margin of $1 \mathrm{~cm}$; only with electrodes that produce a well-documented, regular and predictable ablation zone. It is expected that RCT can provide higher level evidence for the utility of RFA and pave the way for the future application of RFA in the treatment of resectable CLM.

Liveraghi et al [52] proposed to conduct RFA ablation during the interval between diagnosis and resection as a "test-of-time" therapeutic option. The patients whose lesions were treated adequately after RFA ablation may avoid surgical resection and if it was found tumor residence or local recurrence after RFA, surgical resection was then processed. 88 consecutive patients with 134 colorectal carcinoma liver metastases who were potential candidates for hepatic metastasectomy were undergone RFA ablation. Among the 53 patients who achieved complete tumor ablation after RFA, 52 (98\%) were spared surgical resection; 23 $(44 \%)$ remained free of disease, $29(56 \%)$ developed disease progression and no patient who had been treated with RFA ablation became unresectable due to the growth of metastases. It provides a novel way of RFA as the first-line therapy that can avoid unnecessary surgery.

\section{Conclusions}

Since currently no RCT data are available for treating CLM patients, the vast majority of studies included in this meta-analysis comparing the effect of RFA and LR are retrospective. Liver resection provided superior OS and DFS over RFA, even when performed on tumor $<3 \mathrm{~cm}$ or solitary tumor, or using open/lap approach. Conversely, RFA shows advantage over surgical resection in morbidity and length of hospital stay. Due to a lower OS and DFS after RFA suggested by the meta-analysis, caution should be taken when treating CLM with RFA before more supportive evidence for RFA treatment are obtained from RCTs.

\section{Supporting Information}

Flow of Included Studies S1 The flow diagram depicts the flow of information through the different phases of our systematic review. It maps out the records identified, included and excluded, and the reasons for exclusions.

(DOC)

PRISMA S1 The PRISMA checklist contains items pertain to the content of reviewed papers which include the title, abstract, methods, results, discussion and funding.

(DOC)

\section{Author Contributions}

Conceived and designed the experiments: MZW YZ ZWQ WG. Analyzed the data: MZW YZ DZ ZHT MNZ YY ZWQWG. Contributed reagents/ materials/analysis tools: MZW DZ WG. Wrote the paper: MZW WG. 


\section{References}

1. American Cancer Society (2002) Cancer facts and figures. Washington, DC: American Cancer Society.

2. Bengtsson G, Carlsson G, Hafstrom L, Jonsson PE (1981) Natural history of patients with untreated liver metastases from colorectal cancer. Am J Surg 141(5): 586-589.

3. Scheele J, Stang R, Altendorf-Hofmann A, Paul M (1995) Resection of colorectal liver metastases. World J Surg 19(1):59-71.

4. Choti MA, Sitzmann JV, Tiburi MF, Sumetchotimetha W, Rangsin R, et al. (2002) Trends in long-term survival following liver resection for hepatic colorectal metastases. Ann Surg 235(6):759-766.

5. Vauthey JN, Pawlik TM, Abdalla EK, Arens JF, Nemr RA, et al. (2004) Is extended hepatectomy for hepatobiliary malignancy justified? Ann Surg 239(5):722-730.

6. Silen W (1989) Hepatic resection for metastases from colorectal carcinoma is of dubious value. Arch Surg 124(9):1021-1022.

7. Zhou XD, Tang ZY (1998) Cryotherapy for primary liver cancer. Semin Surg Oncol 14(2):171-174

8. Danila M, Sporea I, Sirli R, Popescu A (2009) Percutaneous ethanol injection therapy in the treatment of hepatocarcinoma-results obtained from a series of 88 cases. J Gastrointestin Liver Dis 18(3):317-322.

9. Huo TI, Huang YH, Huang HC, Wu JC, Lee PC, et al. (2006) Fever and infectious complications after percutaneous acetic acid injection therapy for hepatocellular carcinoma: incidence and risk factor analysis. J Clin Gastroenterol 40(7):639-642.

10. Kawamoto C, Ido K, Isoda N, Hozumi M, Nagamine N, et al. (2005) Long-term outcomes for patients with solitary hepatocellular carcinoma treated by laparoscopic microwave coagulation. Cancer 103(5):985-993.

11. Pelletier G, Roche A, Ink O, Anciaux ML, Derhy S, et al. (1990) A randomized trial of hepatic arterial chemoembolization in patients with unresectable hepatocellular carcinoma. J Hepatol 11(2):181-184.

12. Lau WY, Lai EC (2009) The current role of radiofrequency ablation in the management of hepatocellular carcinoma: a systematic review. Ann Surg 249(1):20-25.

13. Shibata T, Iimuro Y, Yamamoto Y, Maetani Y, Ametani F, et al. (2002) Small hepatocellular carcinoma: comparison of radio-frequency ablation and percutaneous microwave coagulation therapy. Radiology 223(2):331-337.

14. Lencioni R, Cioni D, Crocetti L, Bartolozzi C (2004) Percutaneous ablation of hepatocellular carcinoma: state-of-the-art. Liver Transpl (Suppl 1):S91-97.

15. Gillams AR, Lees WR (2005) Radiofrequency ablation of colorectal liver metastases. Abdom Imaging 30(4): 419-426.

16. Oshowo A, Gillams A, Harrison E, Lees WR, Taylor I (2003) Comparison of resection and radio-frequency ablation for treatment of solitary colorectal liver metastases. Br J Surg 90(10): 1240-1243.

17. Elias D, De Baere T, Smayra T, Ouellet JF, Roche A, et al. (2002) Percutaneous radiofrequency thermoablation as an alternative to surgery for treatment of liver tumour recurrence after hepatectomy. Br J Surg 89(6): 752-756.

18. Chen MS, Li JQ, Zheng Y, Guo RP, Liang HH, et al. (2006) A prospective randomized trial comparing percutaneous local ablative therapy and partial hepatecto my for small hepatocellular carcinoma. Ann Surg 243(3): 321-328.

19. Lu MD, Kuang M, Liang LJ, Xie XY, Peng BG, et al. (2006) Surgical resection versus percutaneous thermal ablation for early-stage hepatocellular carcinoma: a randomized clinical trial. Zhonghua Yi Xue Za Zhi 86(12): 801-805.

20. Sørensen SM, Mortensen FV, Nielsen DT (2007) Radiofrequency ablation of colorectal liver metastases: long-term survival. Acta Radio 48(3): 253-258.

21. Mulier S, Ni Y, Jamart J, Michel L, Marchal G, et al. (2008) Radiofrequency ablation versus resection for resectable colorectal liver metastases: time for a randomized trial? Ann Surg Oncol 15(6): 144-157.

22. Begg CB, Mazumdar M (1994) Operating characteristics of a rank correlation test for publication bias. Biometrics 50(4):1088-1101.

23. Hur H, Ko YT, Min BS, Kim KS, Choi JS, et al. (2008) Comparative study of resection and radiofrequency ablation in the treatment of solitary colorectal liver metastases. Am J Surg 197(6):728-736.

24. Oshowo A, Gillams A, Harrison E, Lees WR, Taylor I (2003) Comparison of resection and radiofrequency ablation for treatment of solitary colorectal liver metastases. Br J Surg 90(10):1240-1243.

25. Evrard S, Becouarn Y, Fonck M, Brunet R, Mathoulin-Pelissier S, et al. (2004) Surgical treatment of liver metastases by radiofrequency ablation, resection, or in combination. The Journal of Cancer Surgery. 30(4): 399-406.

26. Abdalla EK, Vauthey JN, Ellis LM, Ellis V, Pollock R, et al. (2004) Recurrence and outcomes following hepatic resection, radiofrequency ablation, and combined resection/ablation for colorectal liver metastases. Ann Surg 239(6):818-825.

27. White RR, Avital I, Sofocleous CT, Brown KT, Brody LA, et al. (2007) Rates and patterns of recurrence for percutaneous radiofrequency ablation and open wedge resection for solitary colorectal liver metastasis. J Gastrointest Surg 11(3): 256-263.
28. Gleisner AL, Choti MA, Assumpcao L, Nathan H, Schulick RD, et al. (2008) Colorectal liver metastases: recurrence and survival following hepatic resection, radiofrequency ablation, and combined resection-radiofrequency ablation. Arch Surg 143(12): 1204-1212.

29. Lee WS, Yun SH, Chun HK, Lee WY, Kim SJ, et al. (2008) Clinical outcomes of hepatic resection and radiofrequency ablation in patients with solitary colorectal liver metastasis. J Clin Gastroenterol. 42(8): 945-949.

30. Berber E, Tsinberg M, Tellioglu G, Simpfendorfer CH, Siperstein AE (2008) Resection versus laparoscopic radiofrequency thermal ablation of solitary colorectal liver metastasis. J Gastrointest Surg 12(11): 1967-1972.

31. Hur H, Ko YT, Min BS, Kim KS, Choi JS, et al. (2009) Comparative study of resection and radiofrequency ablation in the treatment of solitary colorectal liver metastases. Am J Surg 197(6):728-736.

32. Reuter NP, Woodall CE, Scoggins CR, McMasters KM, Martin RC (2009) Radiofrequency ablation vs. Resection for hepatic colorectal metastasis: therapeutically equivalent? J Gastrointest Surg 13(3): 486-491.

33. McKay A, Fradette K, Lipschitz J (2009) Long-term outcomes following hepatic resection and radiofrequency ablation of colorectal liver metastases. HPB Surgery. ID 346863:1-8.

34. Otto G, Düber C, Hoppe-Lotichius M, König J, Heise M, et al. (2010) Radiofrequency ablation as first-line treatment in patients with early colorectal liver metastases amenable to surgery. Ann Surg 251(5): 796-803.

35. Lee KH, Kim HO, Yoo CH, Son BH, Park YL, et al. (2011) Comparison of radiofrequency ablation and resection for hepatic metastasis from colorectal cancer. Korean J Gastroenterol. 59(3): 218-223.

36. Kim KH, Yoon YS, Yu CS, Kim TW, Kim HJ, et al. (2011) Comparative analysis of radiofrequency ablation and surgical resection for colorectal liver metastases. J Korean Surg Soc 81(1): 25-34.

37. Kannerup AS, Nielsen DT, Sørensen SM, Mortensen FV (2008) Combined liver resection and radiofrequency ablation for colorectal liver metastases. Ugeskr Laeger.14;170(16):1338-1341.

38. Elias D, Santoro R, Ouellet JF, Osmak L, de Baere T, et al. (2004) Simultaneous percutaneousright portal vein embolization and left liver tumor radiofrequency ablation prior to a major right hepatic resection for bilateral colorectal metastases.Hepatogastroenterology.51(60):1788-1791.

39. Leblanc F, Fonck M, Brunet R, Becouarn Y, Mathoulin-Pelissier S, et al. (2008) Comparison of hepatic recurrences after resection or intraoperative radiofrequency ablation indicated by size and topographical characteristics of the metastases. EJSO. 34 (2): 185-190.

40. Majeed AW (2003) Comparison of resection and radiofrequency ablation for treatment of solitary colorectal liver metastases. Br J Surg 90(10): 1240-1243.

41. Abdalla EK, Adam R, Bilchik AJ, Jaeck D, Vauthey JN, et al. (2006) Improving resectability of hepatic colorectal metastases: expert consensus statement. Ann Surg Oncol 13(10): 1271-1280.

42. Wagner JS, Adson MA, Van Heerden JA, Adson MH, Ilstrup DM (1984) The natural history of hepatic metastases from colorectal cancer: a comparison with resective treatment. Ann Surg 199(5): 502-508.

43. Goldberg SN, Charboneau JW, Dodd GD III, Dupuy DE, Gervais DA, et al. (2003) Image-Guided Tumor ablation: proposal for standardization of terms and reporting criteria. Radiology. 228(2):335-345.

44. Berber E, Herceg NL, Casto KJ, Siperstein AE (2004) Laparoscopic radiofrequency ablation of hepatic tumors: prospective clinical evaluation of ablation size comparing two treatment algorithms. Surg Endosc 18(3):390-396.

45. Mulier S, Ni Y, Jamart J, Ruers T, Marchal G, et al. (2005) Local recurrence after hepatic radiofrequency coagulation: multivariate meta-analysis and review of contributing factors. Ann Surg 242(2): 158-171.

46. Hildebrand P, Leibecke T, Kleemann M, Mirow L, Birth M, et al. (2006) Influence of operator experience in radiofrequency ablation of malignant liver tumours on treatment outcome. Eur J Surg Oncol 32(4): 430-434.

47. Solbiati L, Ierace T, Livraghi T, Meloni F, Goldberg SN, et al. (2001) Outcome and long-term survival of patients with liver metastases from colorectal cancer treated with percutaneous cool-tip radiofrequency ablation. Radiology. 221(1): 625-626.

48. Gillams AR, Lees WR (2005) Radiofrequency ablation of colorectal liver metastases. Abdom Imaging. 30(4):419-426.

49. Wood TF, Rose DM, Chung M, Allegra DP, Foshag LJ, et al (2000) Radiofrequency ablation of 231 unresectable hepatic tumors: indications, limitations, and complications. Ann Surg Oncol 7(8): 593-600.

50. Wu YZ, Li B, Wang T, Wang SJ, Zhou YM (2011) Radiofrequency ablation vs hepatic resection for solitary colorectal liver metastasis: a meta-analysis. World J Gastroenterol. 28;17(36):4143-8.

51. Mulier S, Ruers T, Jamart J, Michel L, Marchal G, et al. (2009) Radiofrequency ablation versus resection for resectable colorectal liver metastases: time for a randomized trial? Dig Surg 25(6): 445-460.

52. Livraghi T, Solbiati L, Meloni F, Ierace T, Goldberg SN, et al. (2003) Percutaneous radiofrequency ablation of liver metastases in potential candidates for resection. The "Test-of-Time" approach. Cancer. 97(12): 3027-3035. 